\title{
Comparism study between internal \& external lateral osteotomy in rhinoplasty operations
}

Volume 6 Issue 2 - 2017

Keywords: lateral osteotomy, rhinoplasty, remodeling external, percutaneous osteotomy

\section{Introduction}

Lateral osteotomy is known as a major part of rhinoplasty for Remodeling external face of the nose and narrowing the nasal base and Dorsum after removal of the hump there are several approaches for Lateral osteotomy, namely percutaneous, intranasal, and intraoral. ${ }^{1}$ The two most common approaches are external percutaneous Osteotomy and the internal continuous endonasal technique. The osteotomies are performed blindly using tactile guidance. ${ }^{2}$ Among the various step of rhinoplasty, surgeon has less control on the lateral osteotomy because of oedema and hematoma. ${ }^{3}$ There are many reports about the complications of lateral osteotomy, such as infection, bleeding, massive oedema, lacrimal duct injury, intracranial injuries disfigured appearance, narrow air way and nasal Obstruction. ${ }^{4}$

\section{Materials and methods}

A retrospective study was done of total 30 patients who were operated for rhinoplasty in AL-Yarmuk hospital All 12 patients who had undergone internal/endonasal continuous Lateral osteotomy were compared with 18 patients who had undergone External / percutaneous performing digital osteotomy. The scoring system for oedema and ecchymosis was following (as modified from Kara and Gokalan in 1999). ${ }^{5}$ Scoring system for edema. Grade I No coverage of iris with eyelids. Grade 11 Slight coverage of iris with swollen of eyelids. Grade 111 full coverage of iris with swollen of eyelids. Grade IV full closure of eyes. Scoring system of ecchymosis Grade I ecchymosis up to medial one third part of lower and /or upper eyelids. Grade 11 ecchymosis up to medial two third parts of lower and /or upper eyelids. Grade 111 ecchymosis up to full length and / or upper eyelids.

\section{Operative procedure}

The 12 of patients in this study had undergone endonasal High to Low to High continuous lateral osteotomy with $3 \mathrm{~mm}$. curved Guarded osteotome and the 18 patients had undergone percutaneous perforating digital osteotomy.

\section{Continuous lateral osteotomy}

The proposed line of osteotomy was marked with marking pen for the accurate path of osteotomy. The lateral osteotomy was done by giving small incision at pyriform aperture just above the level of attachment of inferior turbinate, periosteum was elevated only $2 / 3$ of it is length by periosteum elevator' the osteotome was engaged and passed along sulcus of frontal process of maxilla (nasofacial groove) with tap stroke of mallet the purpose of first tapis to engage the osteotome and is done always with light force at short distance from the base of osteotome and second tap is done with more distance and force from the base of osteotome to introduce and move it further. The osteotome was gently curved medially as approaches the infra orbital rim and continue superiorly about level of intercanthalline.

\author{
Adnan Qahtan Khalaf,' Ferayl Shakir Taher,',2 \\ Hazim Mohammed Khudhair ${ }^{1,2}$ \\ 'Al Yarmouk Teaching Hospital Ministry of Health, Iraq \\ ${ }^{2}$ Medical city hospital M.O.H, Iraq
}

Correspondence: Adnan Qahtan Khalaf Al Yarmouk Teaching hospital Ministry of health, Iraq, Email khtan@yahoo.com

Received: February 19, 2017 | Published: March 09, 2017

\section{Percutaneous perforating digital osteotomy}

A stab incision was given at midpoint between vestibule and medial Canthus. The tip of $2 \mathrm{~mm}$ osteotome was firmly press of disrupting the lacrimal sac or damage to the medial canthus ligament. It was incised cleanly with tip of osteotome by sweeping the osteotome up and down at the proposed line of osteotomy and perforation of bone was done with $2 \mathrm{~mm}$ shape osteotome. The multiple site bone perforation was done by rotating the osteotome up and down from same sit of skin incision and bone was perforated at $2 \mathrm{~mm}$ distance with tap stroke of mallet. Change of sound of tapping of osteotomy signals that internal cortical bone has broken. All 12 patients who had undergo endonasal continuous lateral osteotomy had periorbital oedema 2 patients (16.6 $\%$ ) had grade I 3 patients (25\%) had grade 116 patients $(50 \%)$ had grade 1111 patients $(8.3 \%)$ had grade $1 \mathrm{~V}$.

\section{Results}

The ecchymosis of grade I was found in 9 patients $(75 \%)$ All patients were given the injectable dexamethasone $4 \mathrm{mg}$ three times daily for 1-2 days depending upon the response and grade of individual case along with oral anti-inflammatory. The 18 patients who had undergone percutaneous perforating digital Osteotomy 14 patients (77\%) grade I 3 patients $16.6 \%$ grade 111 patient grade 111 . The ecchymosis of grade I was found in 3 patients $16.6 \%$.

\section{Discussion}

The external technique was used by coria in $1955^{6}$ and popularized by straatsms. ${ }^{7}$ This technique causes less tear of internal mucosa of nose as seen in cadaver studies. The preservation of periosteum in external technique provides control on bleeding, edema and ecchymosis . Only 8 patients had edema of grade 11 And 14 patients had edema of grade I and only 3 patients had ecchymosis. However y. ${ }^{8}$ in his study found the same score in both internal and external osteotomy groups for both edema and ecchymosis. Gvyskiewicz (9) carried out lateral osteotomy in 50 patients ( 25 patient's external 
osteotomy +25 patients internal) and found that external are reduces post-operative ecchymosisi and edema compared with internal one. Giacomarra et al., ${ }^{10}$ also found perforating osteotome an easy and precise approach reduced bleeding and edema formation around eye. Rochrich et al., ${ }^{11}$ performed anatomical study of 19 fre. Cadavers head to compare lateral nasal osteotomies using internal and external Technique. They used direct nasal endoscope to evaluate the nasal mucosa after osteotomy and found mucosal tear $71 \%$ cases of external osteotomy as compared $74 \%$ mucosal tear in internal osteotomy.

\section{Conclusion}

External osteotomy is an easy approach to carryout and to make fracture with high precision along preset line. The fracture is greenstick type so the bone stump is stable. There is less bleeding less edema and ecchymosis around eye. The cutaneous scar at site of entry is invisible after the surgery.

\section{Acknowledgments}

None.

\section{Conflicts of interest}

Author declares there are no conflicts of interest.

\section{Funding}

None.

\section{References}

1. Giocomarra V, Russolo M, Arnez ZM, et al. External osteotomy in rhinoplasty. Laryngoscope. 2001;111(3):433-438.
2. Lee HM, Kang HJ, Choi JH, et al. Rationale for osteotome selection in rhinoplasty. J Laryngol Otol. 2002;116(12):1005-1008.

3. Rohrich RJ, MinoliJJ Adams WP, Hollier LH. The lateral nasal osteotomy in rhinoplasty an anatomic endoscopic comparison of external versus the internal approach. Plast Reconstr Surg. 1997;99(5):1309-1312.

4. Parkers ML, Borowiecki B, Binder W. Functional sequel of rhinoplasty. Ann Plast Surg. 1980;4(2):116-120.

5. Kara CO, Gokalan 1. Effects of single dose of steroid usage on edema. Ecchymosis and intraoperative bleeding in rhinoplasty. Plast reconstr Surg. 1999;104(7):2213-2278.

6. Denecke HJ, Meyer R. Plastic Surgery of the head and neck: Corrective and reconstructive Rhinoplasty New York Springer- Verlag (cross) Reference. 1957.

7. Straatsma CR. Surgery of the bony nose: comparative evaluation of chisel and saw technique. Plast reconstr surg. 1961;28:246-248.

8. Yücel OT. Which type of osteotomy for edema and ecchymosis external or internal. Annals of plastic surgery. 2005;55(6):587-590.

9. Gryskiewicz JM, Gryskiewicz KM. Nasal osteotomies a clinical comparison of the perforating methods versus the continuous technique. Plast Reconstr Surg. 2004;113(5): 1445-1456.

10. Giacomarra V, Russolo M, Arnez ZM, et al. external osteotomy in rhinoplasty. Langoscope. 2001;111(3):433-438.

11. Rohrich Rl, Janis JE, Adam WP, et al. An update on the lateral nasal osteotomy in rhinoplasty: an anatomic endoscopic comparison of external versus the internal approach. Plast Reconstr Surg. 2003;111(7):2461-2462 